\title{
Ocena metod obliczania zużycia energii sportowca zaimplementowanych na urządzeniach z systemem Android
}

\author{
Sylwester Muzyka*, Piotr Wójcik*, Jakub Smołka \\ Politechnika Lubelska, Instytut Informatyki, Nadbystrzycka 36B, 20-618 Lublin, Polska
}

Streszczenie. Artykuł prezentuje dwie metody obliczania energii zużytej podczas wysiłku. Wykorzystują one dane uzyskane przy użyciu sensorów dostępnych na urządzeniach mobilnych z systemem Android. Metody te zostały porównane ze sobą jak i z wynikami spalonych kalorii uzyskanymi z dwóch aplikacji dostępnych w sklepie Google Play. Aplikacje te to Endomondo oraz Sports Tracker.

Słowa kluczowe: zużyta energia; spalone kalorie; Android; sensor

*Autor do korespondencji.

Adresy e-mail: sylwester.muzyka@ pollub.edu.pl, piotr.wojcik3@ pollub.edu.pl

\section{Evaluation of methods for computing athlete's energy expenditure implemented on Android devices}

\author{
Sylwester Muzyka*, Piotr Wójcik*, Jakub Smołka \\ Institute of Computer Science, Lublin University of Technology, Nadbystrzycka 36B, 20-618 Lublin, Poland
}

\begin{abstract}
The article presents two methods of computing calories burned during exercise. They use data obtained using sensors available on mobile devices running Android OS. These methods were compared with each other and with the results obtained from two applications available on the Google Play store. These applications are Endomondo and Sports Tracker.
\end{abstract}

Keywords: consumed energy; calories burned; Android; sensor

${ }^{*}$ Corresponding author.

E-mail addresses: sylwester.muzyka@ pollub.edu.pl, piotr.wojcik3@ pollub.edu.pl

\section{Wstęp}

Aktywność fizyczna jest bardzo ważną częścią życia wielu osób. Jak wiadomo jest też w większości przypadków domeną ludzi prowadzących zdrowy tryb życia. Już w czasach starożytnych rywalizowano między sobą o miano najlepszych w wielu różnych dyscyplinach. Płynący czas powodował wymyślanie coraz to nowszych i ciekawszych dyscyplin. $Z$ jego biegiem zaczęto zapisywać rekordy $\mathrm{z}$ wielu sportowych konkurencji, dzięki czemu rywalizacja stawała się bardziej emocjonująca.

Rozwój techniki spowodował powstanie pierwszego smartfonu pod koniec ubiegłego wieku. Wraz $\mathrm{z}$ rozpowszechnieniem tego wynalazku $\mathrm{w}$ obecnym wieku zaczęły powstawać coraz to bardziej ciekawe i funkcjonalne aplikacje przeznaczone właśnie na urządzenia mobilne. Obecnie wielu użytkowników ma dostęp do aplikacji związanych $\mathrm{z}$ uprawianiem sportu. Pozwalają one na przechowywanie danych na temat swoich osiągnięć, czy też udostępnienie ich znajomym. Aplikacje takie zwiększają motywację ich użytkowników dzięki chęci bicia rekordów własnych lub też cudzych. Najczęściej pozwalają one na zliczanie dystansu czy też spalonych kalorii.

Aktualnie na rynku systemów wykorzystywanych na urządzeniach mobilnych przewodzą dwa, Android oraz iOS.
Zdecydowaną przewagę ma pierwszy z nich. Może się on pochwalić instalacją na około $75 \%$ wszystkich smartfonów [1].

Urządzenia takie posiadają często po kilka czy nawet kilkanaście różnego rodzaju sensorów. Dwa $\mathrm{z}$ nich to GPS, będący czujnikiem lokalizacji, oraz akcelerometr, pozwalający na wykrycie ułożenia telefonu w przestrzeni [2]. Przy ich użyciu aplikacje sportowe mogą zliczać dystans pokonany przez użytkownika, a na jego podstawie spalone przez niego kalorie. Warto zaznaczyć, że nie istnieje żaden oficjalny sposób na ich liczenie, stąd też każda aplikacja może generować różne wyniki dla tych samych parametrów. $Z$ tego też powodu powstało Kompendium Aktywności Fizycznej na Uniwersytecie Stanforda badające tego typu zależności [3].

Celem artykułu jest porównanie dwóch metod liczących zużycie energii podczas wysiłku na podstawie danych zebranych z sensorów urządzeń mobilnych. Pomocna w tym będzie aplikacja stworzona na system Android. Wyniki uzyskane przy wykorzystaniu tych sposobów zostały zestawione $\mathrm{z}$ rezultatami otrzymanymi $\mathrm{z}$ dwóch istniejących aplikacji jakimi są Endomondo oraz Sports Tracker [4, 5]. 


\section{Przegląd metod liczących kalorie}

Kaloria jest to jednostka energii równa około 4,1868 J. Określenie spalone kalorie oznacza natomiast ilość energii jaką zużywa człowiek w czasie wysiłku. Najczęściej stosuje się do tego jednostkę wielokrotną jaką jest kilokaloria [6]. Jak do tej pory nie wyznaczono dokładnego wzoru liczącego kalorie zużyte podczas wysiłku. Tym samym nie istnieje żadna oficjalna metoda ich zliczania. Powodem jest fakt, że na liczbę spalonych kalorii wpływa wiele czynników. Są to dane na temat sportowca jak i aktywności jaką wykonał między innymi jego płeć, wiek, waga, wzrost, poziom zaawansowania, metabolizm oraz intensywność treningu wyrażana na przykład czasem i pokonanym dystansem [3, 7, 8]. Wybrane metody przedstawiono w podpunktach 2.1 i 2.2 .

\subsection{Metoda pierwsza - korzystająca $\mathrm{z}$ pokonanego dystansu}

Pierwsza z nich korzysta jedynie z masy sportowca oraz pokonanego przez niego dystansu. Do wyliczenia zużytej energii wykorzystywane są dwa wzory w zależności od prędkości poruszania się. Wykorzystują one masę sportowca wyrażoną w funtach oraz pokonany przez niego dystans podany w milach. Zaprezentowano je poniżej [9].

Wzór 1 jest używany dla prędkości marszowych, nie większych niż 3,7 mili na godzinę.

$$
b k c=0,57 \cdot m \cdot s
$$

gdzie: $b k c$ - liczba spalonych kalorii [kcal], $m$ - masa sportowca [lbs], $s$ - pokonany dystans [miles].

Natomiast wzór 2 jest wykorzystywany dla prędkości biegowych, powyżej 3,7 mili na godzinę.

$$
b k c=0,72 \cdot m \cdot s
$$

gdzie: $b k c$ - liczba spalonych kalorii [kcal], $m$ - masa sportowca [lbs], $s$ - pokonany dystans [miles].

W dalszej części artykułu sposób ten będzie nazywany również metodą pierwszą.

\subsection{Metoda druga - korzystająca $\mathrm{z}$ pulapu tlenowego i odpowiednika metabolicznego}

Druga metoda wykorzystuje dodatkowo czas aktywności. Opiera się na pułapie tlenowym, który identyfikuje się jako zdolność organizmu do pochłaniania tlenu, czyli liczby mililitrów tlenu jaką jest w stanie pobrać jeden kilogram masy człowieka przez minutę wykonywanej aktywności [10]. Dodatkowo wykorzystywany w tym sposobie jest odpowiednik metaboliczny (MET), będący wskaźnikiem wyrażającym zużycie energii podczas różnych aktywności sportowych. 1 MET jest definiowany jako 1 kilokaloria na kilogram na godzinę, jak również jako 3,5 mililitry na kilogram na minutę [11]. Na tej podstawie podobnie jak wyżej posłużono się dwoma wzorami zależnymi od prędkości [12, $13,14]$.
Wzór 3 jest używany dla prędkości marszowych, nie większych niż 3,7 mili na godzinę.

$$
b k c=\frac{\left(\left(0,1 \cdot \frac{s}{t}\right)+\left(1,8 \cdot \frac{s}{t} \cdot g\right)+3,5\right) \cdot m}{210} \cdot t
$$

gdzie: $b k c$ - liczba spalonych kalorii [kcal], $s$ - pokonany dystans $[\mathrm{m}], t$ - czas aktywności [min], $g$ - nachylenie terenu [\%].

Natomiast wzór 4 jest wykorzystywany dla prędkości biegowych, powyżej 3,7 mili na godzinę.

$$
b k c=\frac{\left(\left(0,2 \cdot \frac{s}{t}\right)+\left(0,9 \cdot \frac{s}{t} \cdot g\right)+3,5\right) \cdot m}{210} \cdot t
$$

gdzie: $b k c$ - liczba spalonych kalorii [kcal], $s$ - pokonany dystans $[\mathrm{m}], t$ - czas aktywności [min], $g$ - nachylenie terenu [\%].

W dalszej części artykułu sposób ten będzie nazywany również metodą drugą.

\section{Aplikacja badawcza}

W celu zbadania opisanych wyżej metod stworzono aplikację na urządzenia $\mathrm{z}$ systemem Android. Zaimplementowano w niej oba te sposoby wykorzystując do tego język obiektowy Java oraz środowisko programistyczne Android Studio. W przykładach 1 oraz 2 pokazano dwie funkcje będące odzwierciedleniem pokazanych w punkcie 2 wzorów zliczających liczbę spalonych kalorii.

Przykład 1. Fukcja obliczająca spalone kalorie na podstawie pokonanego dystansu

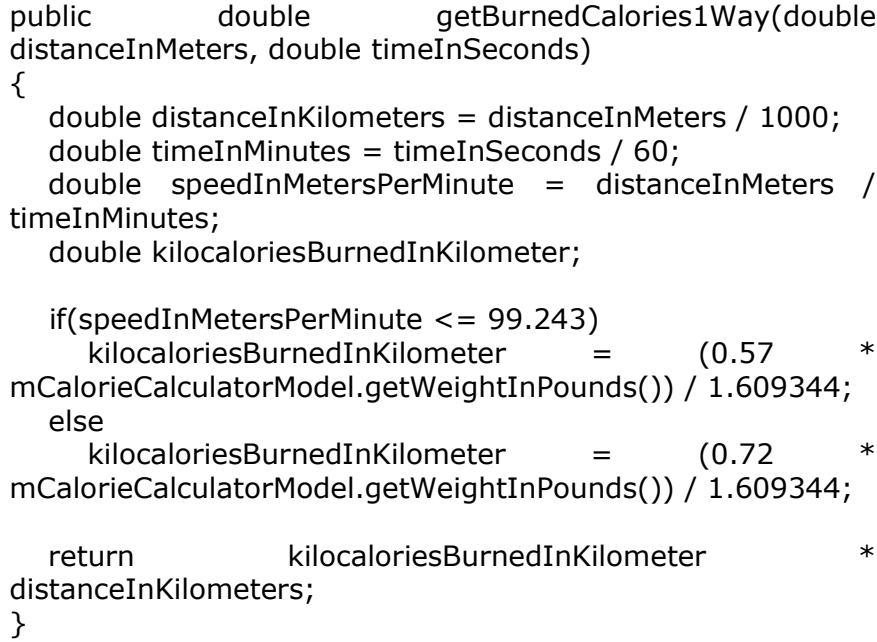

Przykład 1 przedstawia implementację pierwszej metody zliczającej spalone kalorie. Listing ten jest odzwierciedleniem wzorów 1 oraz 2. 
Przykład 2. Fukcja obliczająca spalone kalorie na podstawie pułapu tlenowego oraz odpowiednika metabolicznego

public double getBurnedCalories2Way(double distanceInMeters, double inclinationInPercents, double timeInSeconds)

\{

double timeInMinutes = timeInSeconds / 60;

double speedInMetersPerMinute $=$ distanceInMeters / timeInMinutes;

double inclinationInFraction $=$ inclinationInPercents $/ 100$;

double

oxygenVolumeUsageInMillilitersPerKilogramPerMinute;

if(speedInMetersPerMinute $<=99.243$ )

oxygenVolumeUsageInMillilitersPerKilogramPerMinute = $(0.1 *$ speedInMetersPerMinute $)+(1.8 *$ speedInMetersPerMinute * inclinationInFraction) + 3.5; else

oxygenVolumeUsageInMillilitersPerKilogramPerMinute = $(0.2 *$ speedInMetersPerMinute $)+(0.9 *$ speedInMetersPerMinute * inclinationInFraction) + 3.5;

double oxygenVolumeUsageInMillilitersPerMinute = oxygenVolumeUsageInMillilitersPerKilogramPerMinute mCalorieCalculatorModel.getWeightInKilograms();

double kilocaloriesBurnedPerMinute

oxygenVolumeUsageInMillilitersPerMinute / 210; \}

return kilocaloriesBurnedPerMinute * timeInMinutes;

Przykład 2 przedstawia implementację drugiej metody zliczającej spalone kalorie. Listing ten jest odzwierciedleniem wzorów 3 oraz 4.

\section{Porównanie metod}

W punkcie tym zestawiono ze sobą wyniki badań $\mathrm{z}$ obu omawianych metod. Dodatkowo porównano je z rezultatami uzyskanymi przy pomocy aplikacji Endomondo oraz Sports Tracker. Wyniki zebrano na odległości 611 metrów uzyskanej z uśrednienia długości trasy wyznaczonej w Google Maps oraz MapFactor Navigator. Co więcej, badania były wykonywane przy dwóch różnych prędkościach, marszowej oraz biegowej. Poniżej w tabelach 1, 2 oraz 3 zaprezentowano wyniki otrzymanych pomiarów. Odległości różnią się, ponieważ były wyznaczane za pomocą dwóch metod zliczania dystansu przy użyciu sensorów, jakimi są wcześniej wspomniany GPS oraz krokomierz korzystający z akcelerometru.

Tabela 1. Wyniki pomiarów na dystansie 611 metrów

\begin{tabular}{|c|c|c|c|}
\hline \multicolumn{4}{|c|}{ Spalone kalorie - dystans 611m } \\
\hline Czas (m) & $\begin{array}{c}\text { Zmierzony } \\
\text { dystans (m) }\end{array}$ & $\begin{array}{c}\text { Spalone } \\
\text { kalorie } \\
(\mathbf{1 . ~ m e t o d a )} \\
(\mathrm{kcal})\end{array}$ & $\begin{array}{c}\text { Spalone } \\
\text { kalorie } \\
(\mathbf{2} \text {. metoda) } \\
(\mathrm{kcal})\end{array}$ \\
\hline $06: 55,42$ & 563,24 & 35,18 & 30,69 \\
\hline $06: 58,37$ & 571,46 & 35,7 & 31,07 \\
\hline $07: 03,39$ & 555,77 & 34,72 & 30,58 \\
\hline $07: 29,37$ & 547,55 & 34,2 & 30,84 \\
\hline $07: 25,13$ & 583,41 & 36,44 & 32,12 \\
\hline $07: 02,98$ & 549,05 & 34,3 & 30,31 \\
\hline $07: 00,36$ & 561,74 & 35,09 & 30,74 \\
\hline $06: 51,53$ & 555,77 & 34,72 & 30,32 \\
\hline $04: 03,80$ & 548,25 & 43,26 & 47,19 \\
\hline
\end{tabular}

\begin{tabular}{|c|c|c|c|}
\hline $06: 06,57$ & 553,35 & 34,57 & 29,22 \\
\hline $08: 10,38$ & 617,02 & 38,54 & 34,4 \\
\hline $08: 00,40$ & 612,54 & 38,26 & 34,01 \\
\hline $07: 11,98$ & 604,46 & 37,76 & 32,62 \\
\hline $07: 16,99$ & 665,22 & 41,55 & 35,05 \\
\hline $07: 01,05$ & 625,7 & 39,09 & 33,19 \\
\hline $06: 56,16$ & 627,01 & 39,17 & 33,13 \\
\hline $07: 05,16$ & 619,65 & 38,71 & 33,05 \\
\hline $04: 14,36$ & 587,34 & 46,34 & 50,4 \\
\hline $04: 27,17$ & 597,85 & 47,17 & 51,49 \\
\hline $08: 16,06$ & 630,29 & 39,37 & 35,03 \\
\hline $06: 49,93$ & 473,55 & 29,58 & 27,15 \\
\hline $07: 26,90$ & 505,46 & 31,57 & 29,19 \\
\hline $04: 07,15$ & 554,94 & 43,79 & 47,77 \\
\hline $04: 08,99$ & 571,26 & 45,08 & 49,06 \\
\hline $04: 08,35$ & 560,15 & 44,2 & 48,2 \\
\hline $04: 09,15$ & 552,5 & 43,6 & 47,63 \\
\hline $06: 46,27$ & 571,46 & 35,7 & 30,8 \\
\hline $07: 06,53$ & 581,17 & 36,3 & 31,62 \\
\hline $04: 07,34$ & 533,8 & 42,12 & 46,17 \\
\hline $07: 20,09$ & 572,2 & 35,74 & 31,58 \\
\hline $04: 12,29$ & 560,15 & 44,2 & 48,28 \\
\hline $06: 47,33$ & 613,88 & 38,35 & 32,44 \\
\hline $06: 57,98$ & 634,29 & 39,62 & 33,45 \\
\hline
\end{tabular}

Tabela 1 zawiera wyniki uzyskane $\mathrm{z}$ autorskiej aplikacji podczas poruszania się na dystansie 611 metrów.

Tabela 2. Wyniki pomiarów na dystansie 611 metrów $\mathrm{z}$ aplikacji Endomondo

\begin{tabular}{|c|c|c|}
\hline \multicolumn{3}{|c|}{ Endomondo - spalone kalorie - dystans 611m } \\
\hline Czas (m) & $\begin{array}{c}\text { Zmierzony dystans } \\
(\mathrm{m})\end{array}$ & $\begin{array}{c}\text { Spalone kalorie } \\
(\mathrm{kcal})\end{array}$ \\
\hline $07: 06$ & 570 & 36 \\
\hline $06: 57$ & 590 & 40 \\
\hline $04: 01$ & 590 & 52 \\
\hline $08: 03$ & 640 & 40 \\
\hline $03: 00$ & 630 & 50 \\
\hline $04: 03$ & 610 & 53 \\
\hline $07: 21$ & 580 & 37 \\
\hline $03: 58$ & 590 & 52 \\
\hline
\end{tabular}

Tabela 2 zawiera wyniki uzyskane $\mathrm{z}$ aplikacji Endomondo podczas poruszania się na dystansie 611 metrów.

Tabela 3. Wyniki pomiarów na dystansie 611 metrów z aplikacji Sports Tracker

\begin{tabular}{|c|c|c|}
\hline \multicolumn{2}{|c|}{ Sports Tracker - spalone kalorie - dystans 611m } \\
\hline Czas (m) & $\begin{array}{c}\text { Zmierzony dystans } \\
(\mathrm{m})\end{array}$ & $\begin{array}{c}\text { Spalone kalorie } \\
(\mathrm{kcal})\end{array}$ \\
\hline $03: 59$ & 580 & 47 \\
\hline $08: 07$ & 600 & 35 \\
\hline $03: 59$ & 590 & 49 \\
\hline $03: 41$ & 570 & 54 \\
\hline $06: 40$ & 610 & 50 \\
\hline $06: 24$ & 630 & 61 \\
\hline $04: 08$ & 580 & 46 \\
\hline $07: 13$ & 570 & 35 \\
\hline $04: 01$ & 590 & 49 \\
\hline $07: 25$ & 580 & 34 \\
\hline $03: 57$ & 590 & 48 \\
\hline $07: 15$ & 580 & 34 \\
\hline
\end{tabular}


Tabela 3 zawiera wyniki uzyskane $\mathrm{z}$ aplikacji Sports Tracker podczas poruszania się na dystansie 611 metrów.
Poniżej natomiast wszystkie dane $\mathrm{z}$ tabel 1,2 oraz 3 zaprezentowano na wykresie (rys. 1) w celu łatwiejszej ich oceny oraz porównania.

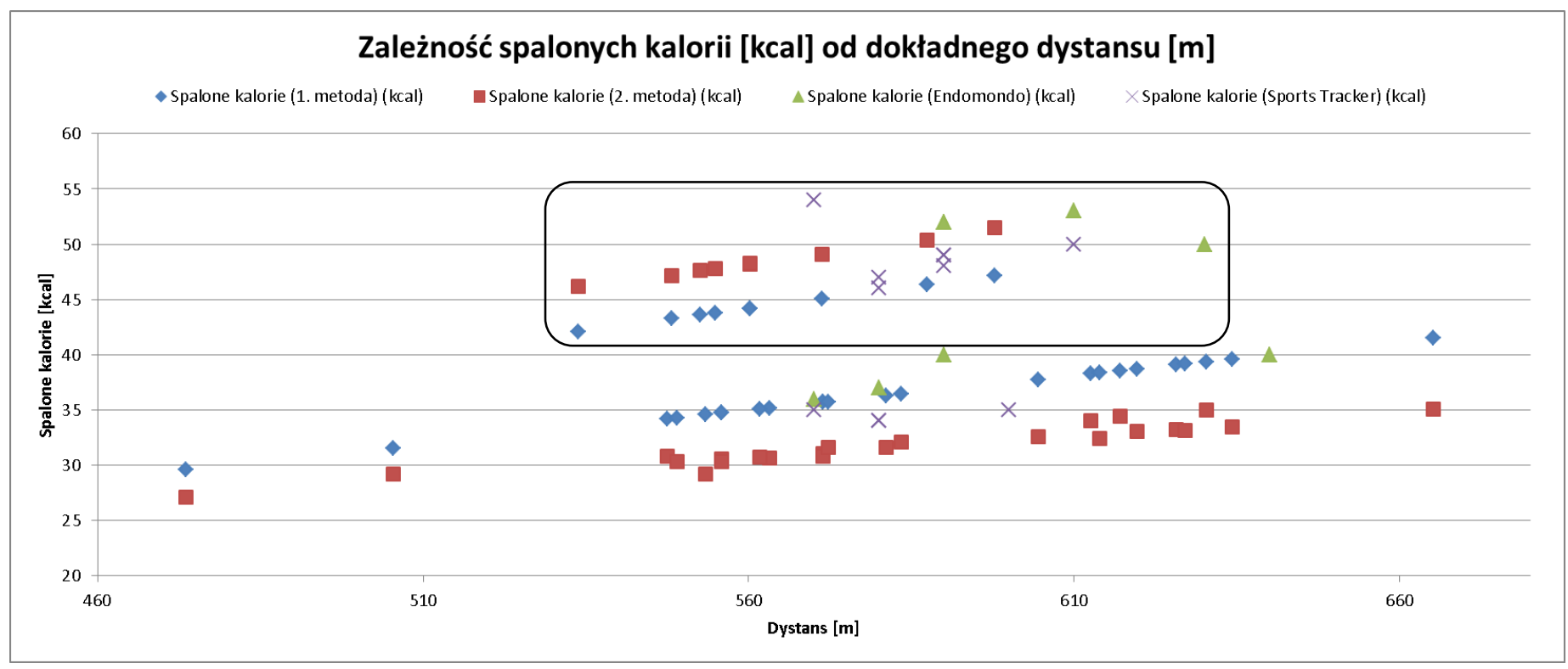

Rys. 1. Zależność spalonych kalorii od dokładnego dystansu (obszar zaznaczony - wyniki uzyskane podczas biegu, pozostały obszar - wyniki uzyskane podczas marszu)

Rysunek 1 przedstawia wykres będący zestawieniem danych zebranych w tabelach 1, 2 oraz 3. Zaznaczony obszar to wyniki uzyskane podczas biegu, natomiast pozostałe reprezentują energię zużytą podczas marszu. Wykres ten pokazuje, że w przypadku badanych metod na obu prędkościach wraz ze wzrostem dystansu liczba spalonych kalorii rośnie. Podczas chodu wyższe wyniki zwraca sposób korzystający jedynie z masy sportowca oraz dystansu jaki pokonał. Bieg natomiast powoduje odwrócenie tej relacji, w związku z czym większa ilość zużytej energii jest wskazywana przez metodę opierającą się na pułapie tlenowym oraz odpowiedniku metabolicznym. Sposób ten dodatkowo korzysta z czasu aktywności.

Wyniki uzyskane z aplikacji Endomondo oraz Sports Tracker korzystają z większej ilości danych przez co, jak mawiają twórcy tej pierwszej, powinny być bardziej dokładne [8]. Obie oprócz masy sportowca, pokonanej przez niego odległości oraz czasu aktywności wykorzystują dodatkowo płeć użytkownika oraz jego wiek. Powyższy wykres pokazuje, że zużyta energia uzyskana za pomocą omawianych w tym artykule metod pokrywa się z wynikami otrzymanymi z tych aplikacji. Jest to potwierdzeniem tego, że badane sposoby są porównywalne z tymi użytymi w aplikacjach Endomondo oraz Sports Tracker.

Aby możliwe było dokładniejsze określenie, która $\mathrm{z}$ omawianych metod jest bardziej precyzyjna wyliczono względne błędy pomiarów. Skorzystano z poniższego wzoru.

$$
\delta=\left(\frac{\left|x-x_{o}\right|}{x}\right) \cdot 100 \%
$$

gdzie: $\delta$ - względny błąd pomiaru, $x$ - wartość dokładna, $x_{o}-$ wartość zmierzona.

Jako, że nie ma oficjalnego wzoru na spalone kalorie, za wartość dokładną uznano uśrednione wyniki z aplikacji Endomondo oraz Sports Tracker wyznaczone dla dokładnej odległości, to znaczy 611 metrów, podanej ręcznie w obu tych aplikacjach. Za wartość zmierzoną uznano natomiast liczbę spalonych kalorii uzyskaną przez podstawienie tego dystansu do wzorów 1, 2, 3 oraz 4. Zabiegi te wykonano w celu osiągnięcia prawidłowej wartości błędów pomiarów. Gdyby zamiast 611 metrów podstawić uśrednione odległości, to błędy zostałyby wyliczone na różnych dystansach. Nie byłyby one więc miarodajne. Za czas w aplikacjach oraz metodzie korzystającej $\mathrm{z}$ pułapu tlenowego podstawiono uśredniony czas uzyskany $\mathrm{z}$ badań opisywanych metod oddzielnie dla marszu oraz biegu. $\mathrm{W}$ ten sposób otrzymano wyniki, które prezentuje tabela 4 .

Tabela 4. Dane potrzebne do wyliczenia błędów pomiarów

\begin{tabular}{|c|c|c|c|c|c|c|}
\hline $\begin{array}{c}\text { Rodzaj } \\
\text { aktywn } \\
\text { ości }\end{array}$ & $\begin{array}{c}\text { Dysta } \\
\text { ns (m) }\end{array}$ & $\begin{array}{c}\text { Uśredni } \\
\text { ony czas } \\
\text { (min) }\end{array}$ & $\begin{array}{c}\mathbf{1 .} \\
\text { metod } \\
\mathbf{a} \\
\text { (kcal) }\end{array}$ & $\begin{array}{c}\mathbf{2 .} \\
\text { metod } \\
\mathbf{a} \\
\text { (kcal) }\end{array}$ & $\begin{array}{c}\text { Endom } \\
\text { ondo } \\
\text { (kcal) }\end{array}$ & $\begin{array}{c}\text { Sports } \\
\text { Tracker } \\
\text { (kcal) }\end{array}$ \\
\hline marsz & 611 & $07: 10,12$ & 38,17 & 32,84 & 40 & 34 \\
\hline bieg & 611 & $04: 10,54$ & 48,21 & 52,13 & 53 & 50 \\
\hline
\end{tabular}

Na podstawie tabeli 4 za pomocą wzoru 5 wyznaczono poniżej zebrane błędy pomiarów. Pod $x$ podstawiono uśrednione zużycie energii $\mathrm{z}$ aplikacji Endomondo oraz Sports Tracker dla badanej odległości (611 metrów). Za $x_{o}$ uznano natomiast spalone kalorie wyliczone za pomocą obu metod (punkt 2.1 oraz 2.2) również dla badanej odległości. Względne błędy pomiarów przedstawiono w tabeli 5. 
Tabela 5. Względne błędy pomiarów

\begin{tabular}{|c|c|c|c|c|c|}
\hline $\begin{array}{c}\text { Rodzaj } \\
\text { aktywno } \\
\text { ści }\end{array}$ & $\begin{array}{c}\text { Dystans } \\
(\mathbf{m})\end{array}$ & Metoda & $\mathbf{x}_{\mathbf{0}}$ (kcal) & $\mathbf{x}$ (kcal) & $\begin{array}{c}\text { Względn } \\
\mathbf{y} \text { bląd } \\
\text { pomiaru }\end{array}$ \\
\hline marsz & 611 & 1 & 38,17 & 37 & $3,16 \%$ \\
\hline marsz & 611 & 2 & 32,84 & 37 & $11,24 \%$ \\
\hline bieg & 611 & 1 & 48,21 & 51,5 & $6,39 \%$ \\
\hline bieg & 611 & 2 & 52,13 & 51,5 & $1,22 \%$ \\
\hline
\end{tabular}

Tabela 5 przedstawia względne błędy pomiarów. Według nich metodą bardziej dokładną jeśli chodzi o liczenie kalorii podczas marszu była ta korzystająca jedynie z masy sportowca i dystansu jaki pokonał. Błąd pomiaru jaki został wyliczony w jej przypadku to około $3,16 \%$. Świadczy to o tym, że podczas chodu czas jest mało znaczącym czynnikiem [15]. Podczas biegu natomiast bardziej dokładne dane zwracała metoda korzystająca z pułapu tlenowego oraz współczynnika metabolicznego. Wynik błędu pomiaru to jedynie około $1,22 \%$, co świadczy o jeszcze bardziej dokładnych rezultatach zużycia energii oraz o tym, że podczas biegu czas jest ważniejszy niż w przypadku marszu.

\section{Wnioski}

Celem artykułu było porównanie dwóch metod liczących zużycie energii podczas wysiłku na podstawie danych zebranych $\mathrm{z}$ sensorów urządzeń mobilnych. Został on zrealizowany poprzez skonfrontowanie ze sobą dwóch metod wykorzystujących dystans wyznaczony przy pomocy dostępnych czujników. Jako, że nie istnieje oficjalny sposób zliczania kalorii to za punkt odniesienia uznano dobrze znane aplikacje ze sklepu Google Play, Endomondo oraz Sports Tracker. Na ich podstawie możliwe okazało się stwierdzenie, że podczas marszu czas nie jest znaczącym czynnikiem, ponieważ dokładniejszą metodą jest sposób nie uwzględniający go w swoim wzorze. Odwrotne wyniki uzyskano w przypadku biegu. W tym przypadku to właśnie metoda wykorzystująca czas zwraca dokładniejsze wyniki pomiarów zużycia energii przez sportowca. Wyniki tego porównania świadczą o tym, że znalezienie odpowiedniego wzoru zliczania spalonych kalorii jest rzeczą bardzo trudną, zwłaszcza, że każdy człowiek jest inny, posiada inną przemianę materii oraz zaawansowanie w uprawianiu sportu, a wykonywane przez niego czynności mają różną intensywność.

\section{Literatura}

[1] http://gs.statcounter.com/os-marketshare/mobile/worldwide/2018, Mobile Operating System Market Share Worldwide [22.11.2018]

[2] Greg Milette, Adam Stroud, Professional Android Sensor Programming, John Wiley \& Sons, 2012

[3] https://sites.google.com/site/compendiumofphysicalactivities, Compendium of Physicial Activities [22.11.2018]

[4] https://play.google.com/store/apps/details?id=com.endomondo. android\&hl=pl, Endomondo - Bieganie \& Rower [22.11.2018]

[5] https://play.google.com/store/apps/details?id=com.stt.android\& hl=pl, Sports Tracker - bieganie i jazda na rowerze [22.11.2018]

[6] https://pl.wikipedia.org/wiki/Kaloria, Kaloria [22.11.2018]

[7] Edward J. Coates, Measured Success!, Trafford Publishing, 2005

[8] https://support.endomondo.com/hc/en-us/articles/201861383Calories, Calories [22.11.2018]

[9] http://www.bmi-calculator.net/how-many-calories-do-youburn-walking-or-running-a-mile, How Many Calories Do You Burn Walking or Running a Mile? [22.11.2018]

[10] https://en.wikipedia.org/wiki/VO2_max, $\mathrm{VO}_{2} \max$ [22.11.2018]

[11] https://en.wikipedia.org/wiki/Metabolic_equivalent, Metabolic equivalent [22.11.2018]

[12] Alex A. Lluch, Easy Fat, Carb, and Calorie Counter, WS Publishing Group, 2009

[13] Nicholas Robertson, Comparing Calorie Expenditure and Rating of Perceived Exertion between the Curve and a Motorized Treadmill, Eastern Washington Univeristy, 2014

[14] https://www.livestrong.com/article/34973-calculate-treadmillcalories, How to Calculate Treadmill Calories [22.11.2018]

[15] Karen J Nolan, Jo-Ann Heslin, The Calorie Counter, 6th Edition, Simon and Schuster, 2012 